\title{
NOTAS SOBRE EL MOGOTE. LA IDENTIFICACIÓN DEL SITIO DE TAMUDA, 1921-2021
}

\section{NOTES ON EL MOGOTE. IDENTIFYING THE SITE OF TAMUDA, 1921-2021}

\section{Manuel Jesús PARODI ÁLVAREZ}

Grupo HUM-440, Universidad de Cádiz, C/Mascarón de Proa 2, 4ํE, 11540, Sanlúcar de Barrameda (Cádiz) Correo electrónico: sidiadir@hotmail.com

Resumen: Nos acercamos en los siguientes párrafos al proceso de la correcta identificación del yacimiento arqueológico de Tamuda (junto a Tetuán, Marruecos), cuando se cumplen 100 años de la misma.

Palabras Clave: Tamuda, Tetuán, César Montalbán, Arqueología, Norte de Marruecos, Protectorado.

Abstract: We consider in this pages the identification of the archaeological site of Tamuda (Tetouan, Morocco), in its first centennial (1921-2021).

Keywords: Tamuda, Tetouan, César Montalbán, Archaeology, Northern Morocco, Protectorate.

Sumario: 1. Bibliografía.

El ámbito septentrional de Marruecos pasaría a la condición de Protectorado de España de forma efectiva desde el año 1912 tras la puesta en funcionamiento de los acuerdos suscritos previamente en la Conferencia Internacional de Algeciras de 1906, que vinieron a sancionar una suerte de $s t a-$ tus quo en el ámbito del estrecho de Gibraltar entre Francia y España (de Faramiñán y Gutiérrez, 2007; Delaunay, 2008; Jiménez y Requena, 2007), bajo la muy atenta mirada de Gran Bretaña (siempre celosa de sus rutas marítimas imperiales), quedando marginado el joven II Reich Alemán de un espacio estratégico (el del estrecho de Gibraltar, el Norte de África y el ámbito del Mediterráneo) por el cual la incipiente potencia germánica mostraba un creciente e inquietante interés; España se convertía de este modo en la potencia europea a la cual esta extensa franja del territorio septentrional magrebí se encontraría (política, económica y administrativamente) ligada hasta pasado el ecuador del siglo XX, quedando de este modo definitivamente vedados los intereses territoriales alemanes en el Norte de África en vísperas de la I Guerra Mundial.

Los impulsos y ambiciones de la política exterior germana se cuentan entre los motores remotos (y los no tan remotos) de la implantación efectiva de la presencia hispano-francesa en el entonces Imperio Cherifiano de Marruecos; si la visita del Káiser Guillermo II a Tánger en 1905 sería uno de los detonantes de la convocatoria de la Conferencia de Algeciras, celebrada en 1906 en la citada localidad andaluza, otro factor a añadir sería la "visita" del buque de guerra alemán "Panther" a las costas del atlántico marroquí en 1911, junto con las presiones diplomáticas ejercidas por Alemania en el plano internacional con vistas a establecer una base germana en la localidad costera atlántica marroquí de Agadir (evidencia de que el II Reich alemán no se resignaba a aceptar la situación política internacional derivada dela Conferencia de Algeciras un lustro antes) (Pintor y O'Neill, 2008), algo a lo que otras potencias imperiales como Francia y -especialmente- Gran Bretaña habrían de oponerse con firmeza dado que este afán germánico podría llegar a alterar la situación hegemónica británica en materia naval en el Océano Atlántico, proporcionando una base a la marina de guerra alemana, así como podría poner en solfa el equilibrio conseguido por los franco-británicos tras la Entente Cordiale de 1904; todo ello terminaría por acelerar los procesos y cauces diplomáticos y políticos consecuencia de los acuerdos suscritos en Algeciras en 1906, y todo ello habría así mismo de conducir a la postre (en el clima general prebélico inmediatamente anterior a la I Guerra Mundial) a la efectiva puesta en marcha del Protectorado franco-español sobre Marruecos con el establecimiento para el mismo de dos Zonas, la 
francesa y la española, de acuerdo con lo pactado inicialmente en 1906 y de acuerdo igualmente con los tratados franco-marroquí y franco-español de 1912.

Ya en 1904 España y Francia suscribirían, siguiendo la estela de la Conferencia de Madrid de 1880, un Tratado bilateral sobre Marruecos, en el contexto de una aceleración de los acontecimientos en torno a la construcción de las relaciones de Europa con África en general y con Marruecos en particular, siendo el Imperio Cherifiano uno de los últimos territorios africanos en verse envuelto en los lazos de la red colonial decimonónica europea, como habría de ser igualmente el caso de Libia, desgajada de la soberanía turca en 1911-1912, manu militari, por Italia e incluida en el incipiente Imperio colonial italiano, o Egipto (también separado de la nominal soberanía turca y convertido en protectorado británico a principios del siglo $X X$; en este sentido, y en lo relativo a los intereses de las grandes potencias europeas sobre estos territorios de la orilla meridional del Mediterráneo, hemos de mencionar el revelador Tratado franco-británico sobre Egipto y Marruecos de abril de 1904 (Ruiz-Bravo, 1945: 248), una Declaración conjunta por la que ambos estados imperiales (la Gran Bretaña y Francia) vendrían a repartirse (en la práctica) sus áreas de influencia e interés entre Marruecos (que quedaría en la órbita de Francia) y Egipto (que quedaría para el Reino Unido) (de Madariaga, 2013).

En este contexto geoestratégico mediterráneo es de recordar que en los años inmediatamente anteriores a la I Guerra Mundial (y en el seno del clima de escalada de tensiones previo a dicha conflagración) tuvieron lugar la I y II Guerras Balcánicas (en 1912 y 1913), así como la mencionada conquista italiana de Libia, en 1911 (en perjuicio del periclitante Imperio Otomano); la actividad política y diplomática (y más adelante, militar) en Marruecos ha de ser contemplada en este contexto prebélico, con un marcado acento colonial y geoestratégico; el "reparto" de Marruecos obedece realmente a la política imperialista europea de finales del siglo XIX (recordemos en este sentido, amén de lo señalado, la Conferencia de Berlín de 1885 y el siguiente "reparto" de África), constituyendo uno de los últimos jalones de la misma (para una sinopsis de los diferentes acuerdos secretos -o públicos- entre las potencias occidentales -esencialmente Francia, Gran Bretaña, España, Alemania e Italia- desde fines del siglo XIX y hasta
1912 en relación con Marruecos, acuerdos conducentes finalmente al establecimiento del Protectorado hispano-francés sobre dicho país norteafricano, véanse Remacha Tejada 2007: 78-ss. Y Muñoz Bolaños 2001a: 9-13; para los antecedentes del "reparto" de Marruecos y la Conferencia de Madrid de 1880, vid. Lamouri 2007: 212-ss.; para la cuestión en general, véase de Madariaga 2008; la línea divisoria entre las áreas española y francesa sería revisada en varias ocasiones, como en 1925 -cfr. Boletín Oficial de la Zona no. 14, de 28 de julio de 1925, pg. 175).

Los ritmos de la presencia de España en el territorio marroquí tanto a principios del siglo $\mathrm{XX}$ como antes, ya a mediados del XIX) vendrían marcados por los tonos bélicos. La guerra es el elemento definitorio del establecimiento del Protectorado en la Zona Española desde antes de la propia existencia real y efectiva del mismo; sin detenernos en los conflictos existentes entre los estados de una y otra orilla del Estrecho desde tiempos históricos, y sólo mencionando la que se daría en llamar I Guerra de África, con la breve ocupación por tropas españolas de la ciudad de Tetuán en 1859-1860, bajo el reinado de Isabel II (algo que no sería un hecho aislado, sino que respondía a los impulsos expansivos, de presencia internacional, de época isabelina, frustrados esencialmente por Gran Bretaña, que llevarían a España a mostrar pabellón y a enzarzarse en diversos escenarios geoestratégicos, participando incluso en diferentes conflictos bélicos en distintos contextos, desde el Pacífico chileno hasta (literalmente) la Cochinchina, pasando por el Norte de África (de Alarcón, 1880; Serrallola, 1998), cabe señalar que ya desde el año 1909, con anterioridad a la puesta en práctica de los tratados de 1906 y 1912, España se encontraba de facto en guerra en territorio marroquí (Muñoz, 2001a: 18-ss.), una situación que devendría estructural y que, tras diversos avatares y con hechos bélicos tan conocidos como los desastres del Barranco del Lobo -en 1909- y de Annual -en 1921- y el decisivo desembarco de Alhucemas -en 1925- (Suárez, 1986) no conseguiría superarse definitivamente hasta el año 1927, con la definitiva y completa derrota de los insurgentes independentistas rifeños de Abd el krim el Jatabi y la final imposición de una paz en principio armada que paulatinamente iría dando paso a una paz extensa y real en la Zona Española del Protectorado sobre Marruecos, una situación de paz que habría de mantenerse ya sin mayores alteraciones ni di- 
ficultades en líneas generales hasta el propio fin de los días del mismo Protectorado, en la segunda mitad de los años 50 del siglo pasado XX.

La ocupación efectiva de la ciudad de Tetuán y sus entornos por parte de tropas españolas se llevaría a cabo en el mes de febrero de 1913 (para el paulatino proceso de establecimiento de la autoridad francesa en su Zona y de la española en la Zona Norte de Marruecos tras la aplicación de los resultados de la Conferencia de Algeciras de 1906, cfr. de Madariaga, 2013); entre 1909 y dicho año de 1913, España trataría de aumentar su área de influencia (dando cumplimiento a lo estipulado en Algeciras en 1906) empleando para ello como lanzaderas y como puntas de lanza tres ciudades: Melilla (el Este del territorio), Ceuta (al centro), ambas plazas de soberanía española, y Larache (en el Marruecos occidental atlántico); fruto de dichas líneas estratégicas habría de ser la paulatina ocupación de territorios en torno a los referidos núcleos oriental, central y occidental. En paralelo a las acciones militares se desarrollaría la labor legislativa y administrativa; así y por Real Decreto de 27 de febrero de 1913 se establecería la organización administrativa del Protectorado, creándose la Alta Comisaría (ligada en principio a la Comandancia y el Gobierno Militar de Ceuta) y las 3 Delegaciones que compondrían el núcleo inicial de la administración española de la Zona: las de Asuntos Indígenas, Fomento y Asuntos Financieros, Tributarios y Económicos (Muñoz, 2001b).

La ocupación efectiva de la ciudad de Tetuán y sus entornos por parte de tropas españolas se llevaría a cabo en el mes de febrero de 1913 (para el paulatino proceso de establecimiento de la autoridad francesa en su Zona y de la española en la Zona Norte de Marruecos tras la aplicación de los resultados de la Conferencia de Algeciras de 1906, cfr. de Madariaga, 2013); entre 1909 y dicho año de 1913, España trataría de aumentar su área de influencia (dando cumplimiento a lo estipulado en Algeciras en 1906) empleando para ello como lanzaderas y como puntas de lanza tres ciudades: Melilla (el Este del territorio), Ceuta (al centro), ambas plazas de soberanía española, y Larache (en el Marruecos occidental atlántico); fruto de dichas líneas estratégicas habría de ser la paulatina ocupación de territorios en torno a los referidos núcleos oriental, central y occidental. En paralelo a las acciones militares se desarrollaría la labor legislativa y administrativa; así y por Real Decreto de 27 de febrero de 1913 se establecería la organización administrativa del Protectorado, creándose la Alta Comisaría (ligada en principio a la Comandancia y el Gobierno Militar de Ceuta) y las 3 Delegaciones que compondrían el núcleo inicial de la administración española de la Zona: las de Asuntos Indígenas, Fomento y Asuntos Financieros, Tributarios y Económicos (Muñoz, 2001b).

Recogemos a continuación un esquema del organigrama de la administración española del Protectorado ya en la década de los años 40 del siglo $\mathrm{XX}$, elaborado por el que fuera Delegado de Asuntos Indígenas entre 1944 y 1945 (y antes, Inspector General de la región del Rif), el coronel Emilio Blanco Izaga (Moga, 2009); a título no anecdótico es de observar cómo en dicho esquema administrativo los Servicios de Archivos, Museos y Arqueología aparecen recogidos en el último lugar en el referido organigrama de la Delegación de Cultura, que aparece organizada de la siguiente manera (lo que en el fondo muestra una evidente ordenación jerárquica de los distintos departamentos, una ordenación en la que los citados servicios archivísticos, museísticos y arqueológicos aparecen en último lugar...) de acuerdo con la información ofrecida por el citado coronel Blanco Izaga:

- Delegación de Cultura

- Subdelegación

- Enseñanza Marroquí y Española (con las correspondientes Direcciones e Inspecciones)

- Enseñanza Profesional y Bellas Artes (con Direcciones e Inspecciones)

- Institutos (Franco, Muley Hassan, 2a. Enseñanza Marroquí y Politécnica)

- Consejo Superior de Enseñanza Islámica

- Conservatorio de Música (española, marroquí)

- Servicios de Educación Física y Deportes

- Servicios de Archivos, Bibliotecas, Museos y Arqueológico

De este modo, y como hemos adelantado, el 9 de febrero de 1913, el flamante Alto Comisario de la Zona Española, general Felipe Alfau, obedeciendo órdenes del entonces presidente del Consejo (presidente del gobierno de España), el conde de Romanones, ocuparía la ciudad de Tetuán sin disparar un tiro, en expresión del propio Romanones (Muñoz, 2001a). La situación de dicha ciudad se revelaría comprometida en breve, haciéndose necesario crear un "cordón sanitario" en torno al núcleo tetuaní, ya que la ciudad de Sidi El Mandri se encontraría enclavada en un territorio esen- 
cialmente rebelde, refractario a la autoridad protectoral, controlado por las kabilas y firmemente sometido a la influencia y la autoridad de un personaje capital en aquellos años, el príncipe Muley Ahmed Mohamed El Raisuni (pariente del Sultán y cabecilla militar de la región de la Yebala, luego muerto a manos de Abd el Krim...), cuyas relaciones con España no se caracterizarían en general ni por su cordialidad ni por su estabilidad a lo largo del tiempo.

De esta forma, y para asegurar la tranquilidad y la seguridad de la que ya había sido establecida como capital del Protectorado, la ciudad de Tetuán, se daría paso a medidas como el establecimiento de baterías de artillería en la propia capital tetuaní, al objeto de batir con su fuego las estribaciones del Gorges (monte frontero al Dersa; sobre la ladera de este último se esparcen los perfiles de la ciudad de Tetuán), desde donde las kabilas batían a su vez con su fuego al núcleo tetuaní, así como el establecimiento de puntos fuertes (los famosos "blocaos" entre ellos, especialmente; al margen y amén del sentido y la naturaleza de los blocaos en la Guerra del Rif -puntos fuertes destinados a albergar tropas españolas y a servir como elementos de la cadena de control del territorio frente a los rebeldes rifeños y yebalíes- y consultado el DRAE sobre el significado del término "blocao", tenemos la siguiente respuesta: Blocao, del alemán Blockhaus, "pequeña fortificación"; 1.m. Mil. Fortín de madera que se desarma y puede transportarse fácilmente para armarlo en el lugar que más convenga) a cierta distancia de Tetuán, como forma de asegurar el control del territorio y de alejar en la medida de lo posible el frente de guerra de la propia ciudad. Así, Kudia Tahar hacia el Este, El Mogote hacia el Sur, o Laucién hacia el Oeste, por ejemplo, serían algunos de los puntos fuertes estratégicos establecidos de cara a la defensa de Tetuán, en torno a los cuales se establecería una línea de defensa, como decimos, de la referida ciudad, que se sostendría en líneas generales hasta 1924, cuando se produciría un repliegue de las líneas españolas hacia el núcleo tetuaní con el abandono, por ejemplo, del punto tamudense y la obligada destrucción de la torre defensiva española de El Mogote.

Uno de los puntos en los que en repetidas ocasiones se llevarían a cabo operaciones militares (que se prolongarían en líneas generales entre 1913 -momento de la ocupación española de Tetuán- y 1925-año del desembarco de Alhucemas) sería el de las estribaciones de Beni Hozmar (te- rritorio base de la kabila homónima), al Sur de la ciudad de Tetuán, al pie de las cuales alturas se encuentra precisamente el sitio arqueológico de Tamuda. De este modo los primeros momentos de la presencia española en el yacimiento de Tamuda no habrían de estar relacionados propiamente con la Arqueología, sino con las operaciones militares subsiguientes a la toma de Tetuán. Así, y por ejemplo, a principios del mes de julio de 1913 se lanzarían diversas expediciones militares españolas desde la mencionada Tetuán al objeto de asegurar el control español sobre las inmediaciones de la ciudad y garantizar de este modo el control de los caminos que desde dicha ciudad conducían al Norte (hasta Ceuta), al Este (hasta la pequeña ciudad de Río Martín, en la costa, en la desembocadura del río homónimo, el actual Martil) y al Oeste (en dirección al poblado de Laucién, donde se desarrollarían así mismo varios hechos de armas en ese mismo año) (muchas de estas operaciones fueron recogidas por la prensa española de la época; en este sentido, véase por ejemplo La Vanguardia del 10 de julio de 1913).

El emplazamiento del sitio arqueológico de Tamuda contaba a principios del siglo XX como en época romana con un gran interés estratégico, como supo señalar Manuel Gómez Moreno de forma tan sucinta como acertada en su conocido informe de 1922: "Dominando la cuenca del río y el valle de Uadrás, precisamente en el vado que se abre camino hacia el Sur, por Xexauen, Uazán y Fez, las condiciones estratégicas del sitio resultarían notorias en todo tiempo" (Gómez, 1922). En efecto, su cercanía a la ciudad de Tetuán (de la que lo separan unos $5 \mathrm{Km}$. por el Suroeste), su localización a la orilla del río Martil (antes Martín y mucho antes aún flumen Tamuda), su situación en un cruce de caminos (con núcleos como Tetuán, Xauén o Laucién como referentes en dicho reparto de itinerarios) y su inmediatez a una de las estribaciones de los montes de Beni Hozmar (montañas que en forma de media luna cercan a Tetuán desde el Gorges -al Oeste de la ciudad, inmediato y frontero a la misma-hasta Tamuda, por el Sur, con la tregua del cauce del Martil, desde cuyos altos los rebeldes kabileños hostigaban a las tropas españolas y podían, de no ser desalojados, mantener su control sobre los itinerarios y caminos señalados -especialmente sobre las rutas hacia el Sur de Tetuán) convertían al sitio de la antigua ciudad y castellum de Tamuda en un punto estratégico que pronto habría de convertirse en centro de atención e interés 
de las operaciones militares.

Ya en el mes de junio de 1913 en el marco de una operación militar española dirigida hacia el sector de Laucién (al Oeste de Tetuán), las estribaciones fronteras a Tamuda fueron testigo de un hecho de armas como consecuencia del cual el sitio de dichas estribaciones recibiría el nombre de "Loma Arapiles", por el regimiento que se batió en dicho sector; entre los objetivos de esta acción (anterior a las de julio y septiembre del mismo año y llevada a cabo sólo cuatro meses después de la toma de la capital tetuaní) se encontraba no sólo el de descongestionar la ciudad de Tetuán, sino también asegurar las comunicaciones terrestres directas de la capital tetuaníc on Larache y Tánger así como con Xauen (Muñoz, 2001b: 114-115); tras dichas operaciones de los meses de junio y julio de 1913, en septiembre del mismo año se determinaría establecer una posición militar española en el sitio de Tamuda, que por entonces era conocido como "Suyar el Portugués", es decir "la fortaleza portuguesa" o "el castillo portugués" (sic), a resultas de lo cual se produciría un hecho de armas que volvería a renombrar el lugar con un nuevo nombre (de carácter dual), Izarduy Bajo (en referencia al emplazamiento de Tamuda) e Izarduy Alto (en referencia a los altos de Beni Hozmar donde se encontraba la "Loma Arapiles"), y ello en homenaje al oficial español D. Ángel Izarduy, quien comandaba las fuerzas de infantería que protegían a los ingenieros y zapadores destinados a la construcción del punto fuerte que se quería establecer en el sitio de Tamuda (y que sería conocido como El Mogote), quien fallecería en esta acción de guerra, una muy sangrienta y encarnizada acción de guerra que habría de prolongarse durante varias semanas a lo largo del verano de 1913, con los militares españoles tratando de establecer un punto fuerte en las ruinas de Tamuda y los secesionistas normarroquíes tratando de impedirlo.

Las operaciones militares de los días de septiembre que señalamos tendrían su eco en la prensa del momento; de ese modo contamos con un reflejo de las mismas, por ejemplo, en los ejemplares del periódico $A B C$ de los días 22, 23 y 30 de septiembre de 1913, en cuyas páginas encontramos la narración de aquellos sucesos con mención expresa de los protagonistas de los mismos y del sitio de El Mogote; el ataque que causó la muerte del capitán Izarduy se produjo en los que serían los momentos iniciales de la construcción de la torre de El Mogote, una obra llevada cabo por ingenieros militares españoles, el día 22 de septiembre del año 1913 (ABC de 24 de septiembre de 1913, pg. 7) y la disputa suscitada en torno a su cuerpo inerte entre españoles y marroquíes vino a convertirse en una cuestión de honor para los primeros y de vindicación para los segundos, encarnizándose aún más los combates a causa de esta particular circunstancia y disputándose unos y otros el cuerpo del infortunado oficial que finalmente pudo ser recuperado por las tropas españolas, por un destacamento comandado por el teniente Francisco Franco Bahamonde.

Con este nombre de El Mogote (consultado el DRAE, las tres primeras definiciones que este Diccionario aporta para el término "mogote" son las siguientes: 1. m. Cualquier elevación del terreno que recuerde la forma de un monte; 2.m. Montón de piedras; 3.m. Montículo aislado, de forma cónica y rematado en punta roma) sería denominada la torre (verdaderamente singular por sus dimensiones y volumen, así como por su empaque en el entorno en que se encontraba) construida por los militares españoles en 1913 en el sitio de Tamuda; Manuel Gómez Moreno, al principio de los años 20 el siglo pasado (poco antes de que la torre debiera ser derruida ante la evolución de los acontecimientos bélicos) señala al respecto, en referencia a las ruinas tamudenses, que "...las defiende hoy una torre militar llamada el Mogote" (Gómez, 1922); por César Luis de Montalbán (Montalbán, 1929: 38) sabemos que "...las necesidades de la guerra obligaron a su destrucción..." en 1924, con lo que la vida del torreón militar construido por el ejército español habría abarcado únicamente entre los años 1913 y 1924, de acuerdo con Montalbán, si bien su existencia habría llegado a generar toponimia, de forma que se produciría una transferencia del nombre del torreón (Mogote) al sitio donde dicha estructura defensiva se encontraba, de forma que el sitio arqueológico recibiría por dichos años el nombre de El Mogote a partir de la torre defensiva homónima; de este modo, entre los nombres con los que los avatares militares del momento bautizaron al sitio de Tamuda a principios del Novecientos podemos contar los de Izarduy (con su variantes de Izarduy Bajo e Izarduy Alto o "Loma de Arapiles", en las estribaciones inmediatas al sitio) y El Mogote, sin olvidar el nombre de "Suyar el Portugués" con el que el sitio era conocido con anterioridad a su reconocimiento por César Luis de Montalbán y Mazas; andando el tiempo el sitio de El Mogote sería empleado como campo de con- 
centración durante la guerra civil española, entre 1936 y 1940 (Alcaraz, 1999: 45-ss.), lo que impediría toda actividad arqueológica en la zona durante dichos años; como sabemos, las actividades de investigación sólo se reanudarían tras la incorporación de Pelayo Quintero Atauri a las estructuras de la Alta Comisaría, a partir de 1939-40, siendo la primera campaña de trabajo de campo de Quintero en Tamuda precisamente la del verano de 1940 (Gozalbes y Parodi, 2014; Parodi, 2007, 2008a, 2008b, 2008c, 2009, 2011, 2017a, 2017b, 2021; Parodi y Gozalbes, 2011; Parodi y Verdugo, 2014; Parodi et al., 2013; Verdugo y Parodi, 2010); serían los trabajos de campo y las publicaciones de Quintero Atauri las que consagrarían para la Historiografía y para la Arqueología el nombre de Tamuda (el nombre histórico del sitio) para el yacimiento, quedando paulatinamente relegadas $(\mathrm{y}$ finalmente abandonadas) las otras denominaciones anteriores del sitio a las que hemos hecho referencia en estos párrafos, y que guardan más relación con los avatares y sucesos bélicos acontecidos en el yacimiento y su entorno que con la propia naturaleza y la historia de este sitio arqueológico, por lo que se habrían visto sujetas a una temporalidad mayor (como se acabaría revelando, con su final caída en desuso) que el nombre histórico del sitio, Tamuda -ya empleado por César Montalbán (Montalbán, 1929-1930)- que, como señalamos, acabaría imponiéndose gracias al rigor de Pelayo Quintero en el desarrollo sistemático de sus trabajos en el sitio y a su también riguroso tratamiento de la información; habría de ser Quintero quien fijase definitivamente para la posteridad el nombre del sitio, Tamuda.

Manuel Gómez Moreno señala en relación con las ruinas de Tamuda que "...el nombre árabe es $\mathrm{Su}$ yar, o sea murete..." (Gómez, 1922); en relación con este término, M. Tarradell señala asimismo (mucho más tarde) que el nombre que recibía el sitio de las ruinas de Tamuda era el de "Suiar", apuntando que éste (el de "Suiar") es el "...nombre que se acostumbra a dar en Marruecos a ruinas antiguas" (Tarradell, 1960: 98); Montalbán por su parte, al explicar cómo fueron los primeros pasos administrativos de sus trabajos en Tamuda (en 19211922, en plena guerra) dice que el presidente de la Junta Superior de Monumentos Históricos y Artísticos [de Marruecos] le encomendó “...los trabajos de exploración en la ruinas conocidas con el nombre de Suyar el Portugués y que desde este momento designaremos con el nombre de Tamuda" (Montalbán,
1929: 28); es de señalar que encontramos bajo la denominación genérica de "portugués" la referencia popular, tradicional, a todos los vestigios arqueológicos antiguos, preislámicos, al menos en el Norte de Marruecos, tal y como en la Península Ibérica no es extraño que se atribuya una naturaleza islámica en el imaginario popular a no pocos sitios arqueológicos, como señala el propio Gómez Moreno en las primeras líneas de su informe: “...atribución usual allí para todo lo antiguo, como entre nosotros se achaca a los moros" (Gómez, 1922); el término "Suiar" (o "Suyar"), usado como nombre propio, denomina a una parte del río que borda la ciudad de Tamuda, significando dicho término "pequeña fortaleza", "pequeña torre", o "castillito", algo que a todas luces parece hacer alusión a las inmediatas ruinas tamudenses (la muralla y carácter militar original de las mismas no se escapaba a quien las contemplase en persona), de acuerdo con lo que señala el historiador de Tetuán Sidi Ahmed R'honi (R'honi, 1953); cfr. Parodi et al., 2013: 65-ss.

Tamuda se encuentra en un relevante eje de comunicaciones (por carretera y por vía férrea), contando conun emplazamiento de privilegiado carácter estratégico (al pié de las estribaciones de los montes de Beni Hozmar), y en el nodo de rutas como las de Xauen y de Ben Karrich, o Laucién (y, en un ámbito de mayor radio, hacia ciudades más occidentales como Tánger o Larache). Hemos contemplado al sitio arqueológico de Tamuda bajo distintas denominaciones, heredada alguna de la tradición popular, como la de "Suyar" o, más extensamente "Suyar el Portugués" (como hemos tenido modo de ver), viniendo otros de los nombres por los que fuera conocido el sitio como consecuencia de los hechos de armas que tuvieron lugar en sus inmediaciones cuando no en el mismo sitio del yacimiento, denominaciones como las de "Izarduy" o El Mogote, nombre este último que, como hemos señalado supra, de la torre defensiva española acabaría extendiéndose al conjunto del sitio. Es de reseñar que el emplazamiento del castellum tamudense (pasados casi dos milenios desde su establecimiento por las armas romanas tras la destrucción de la homónima ciudad mauritana, y perdida ya la capacidad (y la funcionalidad) como vía de comunicación que debió tener el río Martil-Tamuda en tiempos romanos) (Ghottes y Parodi, 2011; Parodi y Ghottes, 2018) continuaría contando con un más que relevante peso estratégico de cara al control del territorio (y las comuni- 
caciones por tierra) a principios del siglo XX como sucediera a mediados del siglo I de la Era, ya que Tamuda se sitúa en un verdadero (y fundamental) eje de comunicaciones, en el que las vías terrestres (las carreteras y el ferrocarril) se encontrarían en el siglo XX cumpliendo el papel, las funciones y los roles que el río Martil (y en menor medida también las vías terrestres) habría de desarrollar en época romana como vía de penetración desde la costa, de comunicación entre la costa y el interior del territorio, y como eje de la vertebración de ese territorio del ángulo oriental de la Yebala, a las puertas del Rif (territorio base de la sublevación contra el sultán).

De lo difícil que debía resultar de forma sostenida la situación de Tamuda a principios del establecimiento del Protectorado (lo que ayuda a explicar al tiempo que justifica la discontinuidad de unos trabajos de investigación arqueológica de campo en el sitio sujetos a las circunstancias bélicas y desarrollados en un terreno no sólo militar sino plenamente sujeto a los avatares de los hechos de armas desde 1913 hasta, al menos, la pacificación definitiva del territorio tras el desembarco de Alhucemas, cumplido el año 1925) es prueba así mismo el hecho (que hemos recogido en otro lugar) (Parodi y Gozalbes, 2011) de que en 1924 se llegara a trabajar en el yacimiento [casi] con fusiles en mano, teniendo que emplear las armas de fuego para rechazar a unos ladrones de ganado, y ello sin contar con acciones bélicas como las de septiembre y diciembre del año 1924 (de las que se da noticia, por ejemplo, en la edición del periódico $A B C$ del día 23 de septiembre de dicho año 1924, así como en La Vanguardia, del 4 de diciembre de 1924), unas operaciones en las que nuevamente las tropas españolas asaltarían las estribaciones de una serranía, la de Ben Karrich, hasta ese entonces nunca sometida por completo a la autoridad de la Alta Comisaría del Protectorado (por más que dichos altos se encontrasen tan sólo a media docena de kilómetros de distancia de la mismísima ciudad de Tetuán). En Tamuda, en El Mogote, se ubicaría no solamente un blocao de infantería, sino que se emplazarían allí igualmente fuerzas de artillería nada desdeñables al objeto de batir con fuego artillero las citadas alturas de Ben Karrich (y de la kabila de los Beni Hozmar) y defender tan crucial nudo de comunicaciones a las afueras de (y en puertas de) la misma capital del Protectorado, Tetuán (vid. el $A B C$ del 18 de diciembre de 1913) (Parodi, 2015a).
Serían, así pues, los hechos militares (continuados) y la situación de permanente tensión bélica los que guiarían los ritmos de los trabajos en Tamuda llevados a cabo por César Luis de Montalbán y Mazas (quien contaría en un principio, de acuerdo con su propio testimonio, con la colaboración del correspondiente de la Real Academia de la Historia Emilio Sanz Álvarez de Tubau (Montalbán, 1929: 28) en los años 20 del pasado siglo XX. El Mogote es, como venimos señalando, la torre que construyen los militares españoles en el verano de 1913 en el sitio del "Suyar" o de "Izarduy Bajo", siendo que, andando el tiempo, la denominación de El Mogote terminaría extendiéndose a toda la zona del yacimiento, como hemos indicado con anterioridad. César Luis de Montalbán, acompañado por Emilio Sanz Álvarez de Tubau y por el coronel Juan Lasquetty, llevaría a cabo en 1921 unas expediciones de reconocimiento por el valle de Tetuán y el cauce del río Martín (entre Tetuán y la ciudad homónima, en la costa), así como por los sectores del Negrón y de Cabo Negro, reconociendo diversos sitios y "estaciones" (prehistóricas, fenicias, cartaginesas o romanas); estas prospecciones pueden ser consideradas como el inicio de los trabajos arqueológicos de campo en el territorio del entonces Protectorado Español en el Norte de Marruecos, las primeras labores sistémicas de campo de carácter arqueológico en el septentrión marroquí, de lo cual se cumplen cien años a la redacción de estos párrafos; de este modo, yacimientos como el de Quitzán, por ejemplo, serían reconocidos (e identificados como tales yacimientos arqueológicos) por Montalbán en dichas campañas expedicionarias de reconocimiento de 1921, las cuales el de Segovia recoge en su Memoria del año 1930 (Montalbán, 1930); el coronel Lasquetty sería asesinado en 1922 (en un atentado en el que podría haber llegado a fallecer incluso el propio Montalbán): la nota de tan luctuoso suceso publicada en el periódico La Vanguardia (en su edición del 17 de agosto de 1922) tilda al fallecido de "escritor cultísimo", señalando igualmente que el coronel Lasquetty era "...uno de los directores de los trabajos de investigación de la ciudad romana de Tamuda.....".

Un ejemplar de esta Memoria (un informe mecanografiado dirigido originalmente a la Junta Superior de Monumentos Históricos y Artísticos que fue redactado en 1930) se conserva en los Fondos Documentales del Museo Arqueológico de Tetuán bajo el título "Estudios sobre la situación de 'Tamu- 
da' y las exploraciones realizadas en la misma por César Luis de Montalbán y de Mazas"; E. Gozalbes Cravioto nos señala que en la Biblioteca Nacional de Madrid (y procedente de la donación de Tomás García Figueras) existe “...otra versión, quizá coincidente con ésta, con el título de 'La situación de Tamuda y exploraciones realizadas en la misma', copia con papel carbón (...) dirigida a la Junta Superior de Monumentos Históricos y Artísticos"; esta copia estaría fechada en agosto de 1929 en Larache, estando compuesta de "...un volumen con 83 hojas y fotografías..." (Gozalbes, 2008a, 2008b: 51-52); en el AGA (el Archivo General de la Administración, en Madrid) existe igualmente otra copia -no completa- de este "Informe-Memoria", la cual nos ha servido para, junto a la conservada en el Museo Arqueológico de Tetuán, poder llevar a cabo el estudio de los trabajos de César Luis de Montalbán y Mazas (véase al respecto Bernal et al., 2013; Gozalbes et al., 2013; Parodi, 2019, 2020).

Tras llevar a cabo distintos trabajos de campo e inspecciones en la misma ciudad de Tetuán, con vistas a identificar y localizar (en su caso) el sitio de la antigua ciudad de Tamuda (Montalbán, 1929-1930), César Luis de Montalbán terminaría por rechazar la hipótesis de identificación de la ciudadde Tetuán con la antigua Tamuda, centrando prontamente su interés en el sitio de El Mogote y por ello efectuando el reconocimiento del contexto de la posición militar conocida por tal nombre, comprobando la existencia de las ruinas de una ciudad antigua (el "Suyar el Portugués" que menciona en su Memoria de 1930, como hemos señalado supra) y relacionando a la postre dichas ruinas con la conocida cita de Plinio (de su Naturalis Historia V, 2, 18); de este modo matizaría (por no decir corregiría) Montalbán al francés Ch. Tissot, quien ya en el siglo XIX (Tissot, 1877) pondría en relación al río Martín con Tamuda, pero identificaría-erróneamente- la antigua ciudad romana con la más moderna ciudad de Tetuán (Montalbán, 1929-1930); en el ámbito de las fuentes clásicas, es de señalar que igualmente mencionan al río $\mathrm{Ta}$ muda (o Tamuada) Pomponio Mela, Chorograhia 1.29, y Claudio Ptolomeo, Geographia, 4.1.3.); finalmente, y como venimos señalando, Montalbán identificaría con todo acierto el lugar de las ruinas de El Mogote con la antigua ciudad de Tamuda.

César Luis de Montalbán y Mazas, quien fuera el primer excavador de Tamuda, y a quien cabe el honor de la identificación plena y correcta de las ruinas de El Mogote o Izarduy Bajo como la ciu- dad romana homónima es autor, entre otros trabajos, del Catálogo de los objetos que existen en el Museo Arqueológico de Tetuán, memoria que pone de manifiesto la existencia del propio Museo, que sabemos ya existía en 1923 (Parodi, 2013a, 2013b, 2018; Zouak y Parodi, 2011, 2012). También habría de complementar el Mapa arqueológico de la zona de Protectorado (1933), una tentativa de implementar una Carta Arqueológica avant la lettre del territorio, e igualmente es de recibo señalar que el mismo Montalbán contaría con cierto éxito en la recuperación de piezas arqueológicas del yacimiento de Tamuda, cuando -algo muy propio del tono de la época- la referida recuperación de materiales considerados "de interés" era uno de los principales objetivos de aquella arqueología tan cargada de un espíritu anticuarista, a la vez tan interesada en el objeto como en el propio sitio arqueológico (cuando no más en el primero que en el segundo...).

Sus trabajos de excavación en el sitio tamudense en los años 1921-1922 (llevados a cabo en el transcurso de dos campañas arqueológicas) tuvieron tintes de auténtica aventura, dadas las condiciones de inseguridad en las que hubo de desarrollarse la tarea, encontrándose el yacimiento de Tamuda en una vital encrucijada de comunicaciones y formando parte, como era el caso, del cinturón defensivo de la propia ciudad de Tetuán (siendo una localización militar, de hecho, como venimos viendo, en el cruce de caminos citado y ante los altos de Ben Karrich), hasta la pacificación definitiva del territorio en torno al bienio 19251927 (en otros trabajos hemos recogido diversas notas sobre los avatares militares del sitio de Tamuda en los años 10 y 20 del siglo XX; cfr. Parodi et al., 2013; Bernal et al., 2013; igualmente, vid. Gozalbes, 2008a: 183-ss., 2008b: 33-ss.; Parodi y Gozalbes, 2011: 137-ss.; Parodi, 2015a); en efecto las acciones bélicas serían una constante en la zona de Tamuda, hasta el punto de imposibilitar por mucho tiempo las tareas de investigación arqueológica en el yacimiento, primando lo militar sobre la investigación en el sitio durante años; la toponimia del lugar así lo demuestra, como venimos viendo, de manera que algunos de los nombres que recibía el lugar, como los citados "Izarduy" (Alto y Bajo) o El Mogote, guardan una relación directa, inmediata, con estas cuestiones y con estos episodios militares de su historia (sobre la continuidad del trabajo arqueológico en la región cfr. Ramos et al., 2015), como señalábamos. 
Pese a la relativa polémica que han querido arrojar desde su misma época sobre los trabajos de Montalbán -una polémica que no es nueva, sino que se pone ya de manifiesto en el propio momento en que los lleva a cabo, en los años 40 del pasado siglo XX, a tenor de la correspondencia triangular entre Pelayo Quintero (responsable del Servicio de Arqueología del Protectorado y protector de Montalbán), Tomás García Figueras (personaje decisivo en la administración de la Alta Comisaría y verdadero factotum de las políticas relacionadas con la gestión del Patrimonio Arqueológico en el Norte de Marruecos cuando menos desde 1939 hasta la desaparición del Protectorado) y el propio César Luis de Montalbán (un perseguido político desde 1936)- lo cierto es que aun considerando el conocimiento general sobre la existencia de unas ruinas en la zona de Beni Hozmar y la curva del río Martín-Martil (el "Suyar" o "Suiar"), y teniendo en cuenta igualmente casos como el precedente del viajero francés A. Joly, quien habría identificado (erróneamente) las ruinas de Tamuda como pertenecientes a una fortificación portuguesa (el "Suyar el Portugués") (Gozalbes ,2005a, 2005b), o de Tissot, quien identificaba Tamuda con Tetuán, cabe enteramente a César Luis de Montalbán y Mazas el mérito de haber sido el primero en reconocer (ya en el año 1921, de lo que se cumplen cien años a la redacción de estos párrafos) en las ruinas donde se encontraba la torre militar defensiva española de El Mogote, los restos de la antigua ciudad romana de Tamuda mencionada por las fuentes clásicas (caso de Plinio, eg., NH., V.2).

El jerezano Tomás García Figueras, militar originalmente (alejado del servicio de armas en 1931), ocuparía diversas Delegaciones en la administración del Protectorado así como la Secretaría General de la Alta Comisaría, y puede ser considerado como el directo responsable de la dinamización de las estructuras de gestión e investigación del Patrimonio Arqueológico de la Zona Española del Protectorado tras la Guerra Civil española; sería obra suya igualmente el afianzamiento de $\mathrm{Ma}$ riano Bertuchi en su puesto como responsable de las Bellas Artes de la Zona, así como puede buscarse en el mismo García Figueras la responsabilidad en el traslado de Quintero a Marruecos (y de este modo la recuperación de este insigne personaje para la investigación y la gestión del Patrimonio Arqueológico en el Norte de África tras su extenso e intenso período gaditano), o la vuelta a la actividad (vigilado y sometido a lo que hoy acaso llama- ríamos acoso laboral, algo a lo que el mismo García Figueras no sería ajeno y que Quintero trataría de suavizar en la medida de sus fuerzas) de César Montalbán tras los avatares por éste sufridos a raíz de la Guerra Civil española (Parodi y Gozalbes, 2011: 184-185); García Figueras sería, finalmente, el impulsor de la creación de una doble estructura en materia de Cultura en el ámbito de la Alta Comisaría: las Bellas Artes, con Mariano Bertuchi al frente, y la Arqueología, con Pelayo Quintero como responsable (al frente de la Inspección General de Excavaciones de la Zona) y como director del flamante Museo Arqueológico de Tetuán (Parodi, 2013a, 2013b, 2018; Zouak y Parodi, 2011, 2012) inaugurado en sus nuevas instalaciones de la calle Ben Hossain (junto al Bajalato y en las inmediaciones del Feddan y la Medina tetuaní el 19 de julio de 1940).

Es bien cierto, en cualquier caso, que Manuel Gómez Moreno es quien primero publica (y de ese modo da a conocer), dicha identificación; de este modo lograría el mérito de dicha identificación de Tamuda para la Historiografía posterior (en su trabajo de 1922), siendo capaz "magistralmente", de acuerdo con Enrique Gozalbes (Gozalbes, 2008b: 51), a quien seguimos, de profundizar en las características y la cronología del sitio a resultas de su visita-inspección del año 1922, y apuntando además en la dirección de la notabilísima relevancia tenida en la Antigüedad por el moderno río Martín-Martil de cara a la ocupación y la gestión del territorio (esto es, de cara a la implantación de Roma en el territorio). En cualquier caso (y como venimos señalando), quien habría identificado en primer lugar la ciudad de Tamuda con las ruinas de El Mogote habría sido César Montalbán, mientras quien habría publicado dicha identidad por vez primera habría sido Gómez Moreno; en este sentido, y con la "sagacidad" que justamente le reconoce alguno de los autores que más hayan estudiado este yacimiento tamudense (Campos et al., 2008: 533, n. 3), Manuel Gómez Moreno señala ya en los años 20 del siglo pasado (siendo capaz hace casi cien años, como atestiguan sus propias palabras, de leer e interpretar correctamente el paleopaisaje de la región del Martil en sus cursos medios y bajo en la Antigüedad) que "...si, como parece, la vega de Tetuán fue un estero en lo antiguo, aquella ciudad pudo ser puerto sobre el río Martín, entonces navegable. Estos datos apoyan su concordancia con el río Tamuda, que cita Plinio, y dichas ruinas con la ciudad del mismo nombre...", ponien- 
do en relación (igualmente por vez primera en una publicación) la cita del tratadista romano Plinio el Viejo (Plinio, N.H. V, 2,18: Ab his ora interni maris. Flumen Tamuda navigabile quondam et oppidum. Flumen Laud est ipsum navigiorum capax) con las ruinas del "Suyar", de El Mogote, esto es poniendo en relación la Tamuda de las fuentes clásicas con las ruinas de Tamuda (Gómez, 1922).

De hecho, un factor decisivo para el poblamiento en esta zona será precisamente el río, tanto en época romana como en época prerromana, el río que (como hemos tenido ocasión de señalar en otros lugares) era el agente articulador del territorio desde la costa hasta cuando menos el que pudo haber sido el límite de su navegabilidad en época antigua, límite que acaso se encontraba precisa y no casualmente en el entorno del emplazamiento de la propia Tamuda (sobre el papel del río Martín-Martil-Tamuda en la Antigüedad en relación con la ciudad de Tamuda, cfr. Ghottes y Parodi, 2011; Parodi y Ghottes, 2018). Finalmente, el hallazgo -producido más adelante en el tiempo (en 1933)- de una inscripción, de un epígrafe latino, permitiría confirmar de manera definitiva el nombre del yacimiento, y, de ese modo, la identificación absoluta y real del mismo; este mérito, en la literatura científica en español, recae sobre los hombros de Pelayo Quintero Atauri (Quintero, 1941b; Thouvenot, 1938).

De este modo, y en lo que respecta al proceso de la construcción de la denominación del sitio y de la identificación del yacimiento tamudense hace ahora un siglo (a la redacción de estos párrafos, a principios de 2021), a César Montalbán corresponde la parte del león de los méritos; sería Montalbán quien primeramente identificase de manera correcta la identidad y la adscripción de las ruinas del sitio del "Suiar el Portugués", poniéndolas en relación con la antigua ciudad de Tamuda, planteando que el sitio debía ser conocido bajo dicha denominación de Tamuda, quedando descartadas de este modo otras -erróneas- hipótesis precedentes que, por ejemplo, identificaban a Tamuda con la ciudad de Tetuán; por su parte, insistimos, Manuel Gómez Moreno sería el primero en publicar dicha identificación (en 1922 y 1924), lo que haría que el mérito de la referida correcta identificación del sitio recayera en un principio (erróneamente) en el erudito granatense en perjuicio de Montalbán; finalmente, Pelayo Quintero Atauri sería quien definitivamente fijase el nombre de Tamuda al yacimiento, debido a sus trabajos de investigación periódicos y a la igualmente periódica publicación de sus Memorias de Excavación del sitio, que llegarían a la Historiografía arqueológica hispana de forma regular en los años 40 del siglo pasado (de forma inmediata al desarrollo de los trabajos y a la publicación de las correspondientes y mencionadas Memorias) contribuyendo de este modo de manera plena a, como decimos, fijar de manera definitiva el nombre del yacimiento (Tamuda) frente a las denominaciones que el sitio conociera anteriormente y que finalmente terminaron por caer en desuso y, con ello, en el olvido (salvo para la Historiografía).

Sería diferente el caso en lo que respecta a la torre militar española, la sobresaliente torre defensiva de El Mogote, pues ni Manuel Gómez Moreno ni César Montalbán en su momento, como tampoco Pelayo Quintero o Miquel Tarradell, respectivamente, años más tarde, llegarían a identificar el origen romano de las bases de esta estructura; dicho mérito recae en el arqueólogo español Javier Verdugo Santos (conservador de Patrimonio de la Junta de Andalucía e investigador de la Universidad de Huelva) quien formulase dicha hipótesis, demostrada finalmente por investigadores de las Universidades de Huelva y Cádiz entre los que se contarían el citado Javier Verdugo y el firmante de estas líneas, entre otros) (Campos et al., 2015). Por su parte Gómez Moreno no se detiene a considerar esta posibilidad; sí recoge, empero, el erudito granadino que las ruinas de Tamuda fueron aprovechadas contemporáneamente por los nativos de la comarca, sirviendo "...de reducto enemigo contra las tropas españolas en campaña reciente...", $\mathrm{y}$ constatando la existencia de la torre militar española "...llamada el Mogote" (Gómez, 1922) haciendo hincapié de esta forma en que se trataba de un territorio en disputa entre las armas españolas y las rebeldes rifeño-yebalíes en aquellos momentos (rebeldes ante la autoridad del sultán marroquí); por la su parte, César Luis de Montalbán y Mazas sí acertará al reconocer la naturaleza romana original de las estructuras sobre las que se establecieron algunos blocaos españoles de la Zona, como el emplazado en Quitzán (Montalbán, 1929-1930: 22-23), unos blocaos al parecer emplazados efectivamente sobre restos y ruinas de estructuras de época romana (reutilizadas más que amortizadas por el ejército español, siglos después de su primer uso), si bien no acierta a reconocer, en cambio, esta reutilización de estructuras romanas en el citado caso de la torre de El Mogote, en el sitio 
de Tamuda (Montalbán, 1929: 24-25), señalando, eso sí, que llegó a reconocer e identificar de manera efectiva la naturaleza romana de las estructuras adyacentes a la referida torre, en el entorno de las cuales se alzaba la misma (se trata del propio corazón del castellum romano de Tamuda; difícil, si se nos permite la apreciación, no reparar en las estructuras adyacentes a la torre de El Mogote, inserta en uno de los ángulos del castellum romano, donde en época romana se alzaría igualmente una torre destinada a la observación defensiva del entorno del catellum).

Para César de Montalbán la torre defensiva de El Mogote (una estructura que el propio Montalbán conoce de primera mano pues prácticamente asiste a su construcción y convive con la misma durante bastante tiempo debido a sus trabajos en el sitio arqueológico tamudense) se alza efectivamente sobre el yacimiento romano, se encuentra completamente rodeada por las estructuras del yacimiento romano, todo lo cual sí reconoce; pero no consta en los párrafos de su Memoria (ni en otros textos suyos) que el segoviano llegase a considerar que las estructuras de la misma pudieran tener un origen romano. Sobre la identificación de El Mogote como torre romana, como hemos adelantado, cabe señalar brevemente que durante la campaña de investigación de apoyo a la conservación realizada en el sitio arqueológico de Tamuda en el año 2008, en desarrollo del Plan Estratégico de la Zona Patrimonial de Tamuda, PET, (Cantero y Verdugo, 2010) se llevó a cabo por el equipo de la Universidad de Huelva, dirigido por el profesor Juan Campos Carrasco, con el apoyo del arquitecto y profesor de la ETSA de Sevilla Juan Antonio Fernández Naranjo (2008), una intervención en la torre noroeste del castellum (Campos et al., 2008) en la que se puso de manifiesto el sistema constructivo de dicho elemento defensivo y se pudo constatar que dicha torre se encontraba muy arrasada debido al deslizamiento del terreno, al ubicarse en una pendiente muy pronunciada frente al río Martil, sobre el que debía ejercer una acción de vigilancia, cabiendo el mérito de la hipótesis interpretativa que primero hablaba del posible origen romano de las estructuras sobre las que se desarrollaba la torre española de El Mogote al arqueólogo español Javier Verdugo Santos.

La evidencia del proceso de deterioro y ruina de la torre Noroeste del perímetro amurallado de Tamuda, de fundamental valor estratégico en la estructura defensiva del castellum así como de cara a la vigilancia sobre el río en la Antigüedad, puso sobre el tapete la hipótesis de que dicha construcción se arruinase ya en la etapa de plena actividad del campamento, lo que supondría que los romanos procedieran a construir intramuros una torre alternativa o complementaria, que sirviese además como punto elevado -como atalaya- con vistas a la observación defensiva del entorno y en especial del río; ante tal posibilidad se procedería a la limpieza y estudio de los restos de la estructura de la torre conocida como El Mogote en la campaña arqueológica de 2011, llevada a cabo en el mes de marzo de 2012, por el equipo de la Universidad de Huelva, con el fin de determinar si la misma, que hasta entonces se había tenido únicamente por una edificación militar española, era en sus primeros orígenes una construcción antigua; los resultados de la campaña acabarían por confirmar la hipótesis (lanzada por J. Verdugo) de que los restos que se conservan de la misma son, en su base y en su primera naturaleza, romanos; ello significaría que el ejército español habría aprovechado los restos aún emergentes de esta construcción antigua para construir sobre ella una nueva estructura en el año 1913 (la de El Mogote), una estructura que sería finalmente "desmontada" por los propios españoles en 1924 ante la presión militar de los insurgentes rifeños y yebalíes contra la autoridad del Majzén (y en último extremo del sultán), y el evidente peligro de que la misma torre llegase a caer en manos de los rebeldes; desde esos entonces los restos existentes se habían considerado como contemporáneos (adscritos al siglo XX) sin repararse en su primera edilicia y estructura, que son de origen romano (para la identificación del origen romano de la torre militar española, y con ello la identificación de una torre romana de ubicación excéntrica respecto al conjunto de la fortificación del castellum de Tamuda -y en el interior de la misma- cfr. Campos et al., 2015).

Así pues, y recapitulando brevemente, en lo que se refiere a la identificación ya centenaria del yacimiento de El Mogote (realizamos una primera aproximación al proceso de identificación del yacimiento de Tamuda -que ahora hemos desarrollado más por extenso- hace unos años; cfr. Parodi, 2015b), señalaremos que Joly erró en su identificación de Tamuda como una antigua fortaleza portuguesa; Tissot identificó correctamente el río Martil con el flumen Tamuda, pero erró al identificar Tetuán con la antigua Tamuda; Montalbán fue el primero en identificar acertadamente las ruinas 
del "Suiar el Portugués" con la ciudad pliniana de Tamuda; Gómez Moreno sería el primero en publicar dicha identificación de las ruinas de El Mogote con Tamuda; Quintero fijaría dicha identificación merced a su publicación del epígrafe de 1933 y a sus trabajos de campo y la publicación de los mismos (Quintero, 1941a, 1942, 1943, 1944, 1945, 1946); Tarradell encontró dicha identificación ya formulada (Montalbán), publicada inicialmente (Gómez Moreno) y fijada definitiva y plenamente (Quintero), limitándose a trabajar con el nombre ya correcto del sitio histórico (Gozalbes y Parodi, 2011). Y de esa correcta identificación del yacimiento, de esa inspiración de Montalbán (así como de sus primeros trabajos de campo en el Norte de África, que es decir del inicio de la Arqueología sistémica de campo en el septentrión marroquí), se cumplen ahora cien años en 2021.

\section{Bibliografía}

de ALARCóN, Pedro A. 1880: Diario de un testigo de la Guerra de África. Madrid.

ALCARAZ CÁNOVAS, Ignacio. 1999: Entre España y Marruecos. Testimonio de una época: 19231975. Catriel. Madrid.

BERNAL CASASOLA, Darío; PARODI ÁLVAREZ, Manuel J.; SÁNCHEZ SALAS, Francisco. 2013: “La Tamuda de Montalbán en el AGA de Madrid. El Dossier de las excavaciones de 1921-1922". En D. BERNAL, B. RAISSOUNI, J. VERDUGO y M. ZOUAK (eds.): Tamuda. La cronosecuencia de la ciudad mauritana y del castellum romano. Resultados del Plan de Investigación del PET (2008-2010), pp. 89-135. Colección de Monografías del Museo Arqueológico de Tetuán, 4. Cádiz.

CAMPOS, Juan; CORTIJO, Victoriano; DELGADO, Salvador; O'KELLY, Jessica; VERDUGO, Javier; VIDAL, Nuria; GHOTTES, Mustapha; RAISSOUNI, Baraka. 2008: "La torre noroeste del castellum de Tamuda (Tetuán, Marruecos): últimos avances sobre su proceso de construcción y evolución histórica". En D. BERNAL; B. RAISSOUNI, J. RAMOS, M. ZOUAK y M. PARODI (eds.): En la Orilla africana del Círculo del Estrecho. Historiografía y proyectos actuales. Colección de Monografías del Museo Arqueológico de Tetuán (MMAT II). Actas del II Seminario Hispano-Marroquí de Especialización en Arqueología, pp. 473-535. Editorial UCA. Cádiz. CAMPOS, Juan; FERNÁNDEZ, Lucía; BERMEJO,
Javier; VERDUGO, Javier; PARODI, Manuel J. 2015: "El blocao del Mogote: el descubrimiento de una 'nueva' torre romana del sistema defensivo tamudense". En J.M. CAMPOS y J. BERMEJO (eds.): El urbanismo militar del Castellum de Tamuda: la castrametación interior., pp. 141-172. L'Erma di Breschneider. Roma.

CANTERO MARTÍNEZ, Jesús; VERDUGO SANTOS, Javier. 2010: Proyecto Tamuda. Parque Cultural y Ambiental. Plan Estratégico de la Zona Patrimonial. Sevilla.

DELAUNAY, Jean Marc. 2008: "Competidores y cómplices. España y Francia en el noroeste de África. Alrededor de la Conferencia de Algeciras". En Actas del Congreso Internacional "La Conferencia Internacional de Algeciras de 1906. Cien años después", pp. 63-75. Fundación Municipal de Cultura José Luis Cano. Algeciras.

DE FARAMIÑÁN GILBERT, Juan M.; GUTIÉRREZ CASTILLO, Víctor L. (coords.). 2007: La Conferencia de Algeciras y las relaciones internacionales. Fundación Tres Culturas del Mediterráneo. Sevilla.

JIMÉNEZ PIERNAS, Carlos; REQUENA CASANOVA, Millán. 2007: "El papel de España en la Conferencia Internacional de Algeciras de 1906". En J.M. DE FARAMIÑÁN y V.L. GUTIÉRREZ (eds.): La Conferencia de Algeciras y las relaciones internacionales, pp. 243-265. Fundación Tres Culturas del Mediterráneo. Sevilla.

GHOTTES, Mustapha; PARODI ÁLVAREZ, Manuel J. 2011: "Le fleuve Tamuda". En M.J. PARODI y E. GOZALBES (eds.): Pelayo Quintero en el primer centenario de 1912, pp. 423-454. Diputación de Cádiz. Cádiz.

GÓMEZ MORENO, Manuel. 1922: "Descubrimientos y antigüedades en Tetuán". Boletín Oficial de la Zona del Protectorado de España en Marruecos, Suplemento al no 10, pp. 5-13.

GÓMEZ MORENO, Manuel. 1924: "Descubrimientos y antigüedades de Tetuán". Revista Hispano-Africana, pp. 9-15.

GOZALBES CRAVIOTO, Enrique. 2005a: "Los pioneros de la arqueología española en Marruecos (1880-1921)". En V. CABRERA, y M. AYARZAGÜENA (eds.): El nacimiento de la Prehistoria $y$ de la Arqueología científica (= Archaia, 3-5), pp. 110-117. Madrid.

GOZALBES CRAVIOTO, Enrique. 2005b: "Los inicios de la investigación española sobre Arqueología y Arte árabes en Marruecos (1860- 
1960)". Boletín de la Asociación española de Orientalistas (BAEO). Año XLI, pp. 225-246.

GOZALBES CRAVIOTO, Enrique. 2008a: "La arqueología española en Marruecos (19211936): memorias y desmemorias". En G. MORA; E. PAPI y M. AYARZAGÜENA (eds.): Documentos inéditos para la Historia de la Arqueología, pp. 183-195. Madrid.

GOZALBES CRAVIOTO, Enrique. 2008b: "Los primeros pasos de la Arqueología en el Norte de Marruecos". En D. BERNAL, B. RAISSOUNI, J. RAMOS, M. ZOUAK y M.J. PARODI (eds.): En la Orilla africana del Círculo del Estrecho. Historiografía y proyectos actuales. Colección de Monografías del Museo Arqueológico de Tetuán. MMAT II. Actas del II Seminario Hispano-Marroquí de Especialización en Arqueología, pp. 33-61. Editorial UCA. Cádiz.

GOZALBES CRAVIOTO, Enrique; PARODI ÁLVAREZ, Manuel J. 2011: "Miguel Tarradell y la Arqueología del Norte de Marruecos". En D. BERNAL (coord.): Actas del III Seminario Hispano Marroquí. Arqueología y Turismo, pp. 198-221. Editorial UCA. Cádiz.

GOZALBES CRAVIOTO, Enrique; PARODI ÁLVAREZ, Manuel J.; VERDUGO SANTOS, Javier. 2013: "Algunas notas sobre Arqueología y colonialismo. La Zona española del Protectorado marroquí, 1912-1945". ONOBA, 1, pp. 261-272.

GOZALBES CRAVIOTO, Enrique; PARODI ÁLVAREZ, Manuel J. 2014: "Pelayo Quintero Atauri: la arqueología entre Cuenca, Cádiz y Marruecos". En E. GOZALBES; M.J. PARODI y A.M. GÁLVEZ (eds.): Pelayo Quintero Atauri (1867-1946). El sabio de Uclés, pp. 15-26. Cuenca.

LAMOURI, Mohamed. 2007: "L'internationalisation de la question marocaine: 1880-1912". En J.M. DE FARAMIÑÁN y V.L. GUTIÉRREZ (coords.): La Conferencia de Algeciras y las relaciones internacionales, pp. 207-220. Sevilla.

de MADARIAGA ÁLVAREZ-PRIDA, María R. 2008: "La Conferencia de Algeciras de 1906: una tregua en el reparto de Marruecos". En Actas del Congreso Internacional "La Conferencia Internacional de Algeciras de 1906. Cien años después", pp. 161-182. Fundación Municipal de Cultura José Luis Cano. Algeciras.

de MADARIAGA ÁLVAREZ-PRIDA, María R. 2013: Marruecos, ese gran desconocido. Breve Historia del Protectorado Español. Madrid.

MOGA ROMERO, Vicente. 2009: El Rif de Emilio Blanco Izaga. Trayectoria militar, arquitectóni- ca y etnográfica en el Protectorado de España en Marruecos. Barcelona-Melilla.

MONTALBÁN Y MAZAS, César L. 1929: Las Mazmorras de Tetuán, su limpieza y exploración. Compañía Iberoamericana de Publicaciones. Madrid.

MONTALBÁN Y MAZAS, César L. 1929-1930: "Estudios sobre la situación de 'Tamuda' y las exploraciones realizadas en la misma por César Luis de Montalbán y de Mazas". Informe mecanografiado inédito dirigido a la Junta Superior de Monumentos Históricos y Artísticos, redactado en 1930. Museo Arqueológico de Tetuán, Fondos Documentales.

MUÑOZ BOLAÑOS, Roberto. 2001a: "La Campaña de 1909". En AA.VV.: Las Campañas de Marruecos 1909-1927, pp. 8-84. Madrid.

MUÑOZ BOLAÑOS, Roberto. 2001b: “Operaciones militares (1910-1918)". En AA.VV. (coord.): Las Campañas de Marruecos 1909-1927, pp. 85-128. Madrid.

PARODI ÁLVAREZ, Manuel J. 2007: "Arqueología española en Marruecos, 1939-1946. Pelayo Quintero de Atauri". SPAL Revista de Prehistoria y Arqueología, 15, pp. 9-20.

PARODI ÁLVAREZ, Manuel J. 2008a: "Notas sobre Historiografía Arqueológica Hispano-Marroquí. 1939-1946, Pelayo Quintero". En D. BERNAL; B. RAISSOUNI; J. RAMOS; M. ZOUAK y M.J. PARODI (eds.): En la Orilla africana del Círculo del Estrecho. Historiografía y proyectos actuales. Colección de Monografías del Museo Arqueológico de Tetuán (MMAT II). Actas del II Seminario Hispano-Marroquí de Especialización en Arqueología, pp. 63-92. Editorial UCA. Cádiz.

PARODI ÁLVAREZ, Manuel J. 2008b: "Pelayo Quintero de Atauri. Apuntes de Arqueología hispano-marroquí, 1939-1946". En J. BELTRÁN y M. HABIBI (eds.): Historia de la Arqueología en el Norte de Marruecos durante el Protectorado y sus referentes en España, pp. 97-119. Universidad Internacional de Andalucía y Universidad de Sevilla. Sevilla.

PARODI ÁLVAREZ, Manuel J. 2008c: "Pelayo Quintero: Arqueología en las dos orillas del Fretum Gaditanum". Atti del XVII Convegno dell'Africa Romana, pp. 2517-2526. Roma.

PARODI ÁLVAREZ, Manuel J. 2009: "Notas sobre la organización administrativa de las estructuras de gestión del Patrimonio Arqueológico en el Marruecos Septentrional durante el Protectorado (1912-1956)". Herakleion, 2, pp. 
117-141.

PARODI ÁLVAREZ, Manuel J. 2011: “Pelayo Quintero. Crepúsculo en Tetuán”. En M.J. PARODI y E. GOZALBES (eds.): Pelayo Quintero en el primer centenario de 1912, pp. 309-322. Diputación Provincial de Cádiz. Cádiz.

PARODI ÁLVAREZ, Manuel J. 2013a: "El Museo Arqueológico de Tetuán, 1923-1948. Algunas notas sobre una Institución del Patrimonio del Norte de África a principios del siglo XX". En Actas de los VI Encuentros de Arqueología del Suroeste, pp. 24-51. Ayuntamiento de Villafranca de los Barros. Mérida.

PARODI ÁLVAREZ, Manuel J. 2013b: “Tetuán, ciudad pionera en la gestión del Patrimonio Arqueológico en el Norte del Reino de Marruecos". En M. CHERIF (coord.): De Al-Andalus a Tetuán. Actas del Homenaje al profesor Mhammad M. Benaboud, pp. 259-288. Universidad Abdelmalek Essaâdi. Tetuán.

PARODI ÁLVAREZ, Manuel J. 2015a: "Arqueología y guerra. Militaria en Tamuda (Tetuán) hace cien años". En N. MEDINA (coord.): Actas de los VII Encuentros de Arqueología del Suroeste, pp. 1227-1249. Ayuntamiento de Aroche. Aroche.

PARODI ÁLVAREZ, Manuel J. 2015b: "La identificación del yacimiento de Tamuda (Tetuán, Marruecos). Algunas notas". En Actas del XX Convegno dell'Africa Romana, pp. 873-884. Roma.

PARODI ÁLVAREZ, Manuel J. 2017a: “Un arqueólogo y gestor de Patrimonio entre las Dos Orillas en la primera mitad del siglo XX. Pelayo Quintero Atauri". En Actas de las XIX Jornadas de Historia de Ceuta, pp. 715-736. Instituto de Estudios Ceutíes. Ceuta.

PARODI ÁLVAREZ, Manuel J. 2017b: "Notas sobre uno de los pioneros de la arqueología española y marroquí. Pelayo Quintero Atauri (18671946) en el $150^{\circ}$ aniversario de su nacimiento". Ligustinus. Revista Digital de Arqueología de Andalucía Occidental, 6, pp. 61-84. http:// revistaligustinus.tk/numero-6-2017/. Fecha de consulta: 27 de agosto de 2021.

PARODI ÁLVAREZ, Manuel J. 2018: "El Museo Arqueológico de Tetuán (1923-1946) en el 150 aniversario del nacimiento de Pelayo Quintero". Anejos de Nailos, 4, pp. 165-182.

PARODI ÁLVAREZ, Manuel J. 2019: "En el I Centenario de la Arqueología del Norte de Marruecos. César Luis de Montalbán y Mazas (18761971), apuntes biográficos de un pionero de la institucionalización del Patrimonio arqueo- lógico". ONOBA, 7, pp. 3-18.

PARODI ÁLVAREZ, Manuel J. 2020: "Notas en el I Centenario de la Arqueología hispano-marroquí. Sobre las actividades arqueológicas en el Norte de África antes de 1936: César Luis de Montalbán". En S. PEREA y M. PASTOR (eds.): El Norte de África en época romana. Tributum in Memoriam Enrique Gozalbes Cravioto, pp. 345-369. Signifer. Monografías y Estudios de Antigüedad griega y romana no. 57. Madrid-Salamanca.

PARODI ÁLVAREZ, Manuel J. 2021: “Quintero Atauri y Tarradell: diarios inéditos de sus excavaciones". En AA.VV. (eds.): Gar Cahal y Tamuda en el archivo Tarradell: historiografía y arqueología en el norte de África occidental, pp. 291-302. Editorial UCA. Cádiz.

PARODI ÁLVAREZ, Manuel J.; GHOTTES, Mustapha. 2018: "Tamuda flumen castellumque. El río Martil como motor del territorio de Tamuda". En Actas de los VIII Encuentros de Arqueología del Suroeste Peninsular, pp. 687-706. Serpa.

PARODI ÁLVAREZ, Manuel J.; GOZALBES CRAVIOTO, Enrique. 2011: "La Arqueología en el Norte de Marruecos (1900-1945)". En AA.VV. (eds.): Actas del III Seminario Hispano Marroquí. Arqueología y Turismo, pp. 175-197. Editorial UCA. Cádiz.

PARODI ÁLVAREZ, Manuel J.; DÍAZ RODRÍGUEZ, José Juan; GHOTTES. Mustapha. 2013: "Cartografiando las antiguas excavaciones de Tamuda. De Montalbán al PET". En D. BERNAL, B. RAISSOUNI, J. VERDUGO y M. ZOUAK: Tamuda. La cronosecuencia de la ciudad mauritana y del castellum romano. Resultados del Plan de Investigación del PET (2008-2010), pp. 65-88. Colección de Monografías del Museo Arqueológico de Tetuán, 4. Cádiz.

PARODI ÁlVAREZ, Manuel J.; VERDUGO SANTOS, Javier. 2014: "El admirable crepúsculo: Pelayo Quintero y la arqueología en el Norte de Marruecos". En E. GOZALBES; M.J. PARODI y A.M. GÁLVEZ: Pelayo Quintero Atauri (1867-1946). El sabio de Uclés, pp. 183-217. Diputación Provincial de Cuenca. Cuenca.

PINTOR ALONSO, Pilar; O'NEILL PECINO, Rosabel. (coords. ed.). 2008: Actas del Congreso Internacional "La Conferencia Internacional de Algeciras de 1906. Cien años después". Algeciras. QUINTERO ATAURI, Pelayo. 1941a: "Excavaciones en Tamuda. Memoria resumen de las excavaciones practicadas en 1940 presentada por 
Pelayo Quintero Atauri". Memoria de la Junta Superior de Monumentos Históricos y Artísticos (MJSMHA), 2. Instituto General Franco para la Investigación Hispano-Árabe. Larache.

QUINTERO ATAURI, Pelayo. 1941b: "Una inscripción latina de Marruecos". Mauritania, 164, pp. 198-199.

QUINTERO ATAURI, Pelayo. 1942: Excavaciones en Tamuda. Memoria resumen de las excavaciones practicadas en 1941 presentada por Pelayo Quintero Atauri. MJSMHA 5. Instituto General Franco para la Investigación Hispano-Árabe. Larache.

QUINTERO ATAURI, Pelayo. 1943: Excavaciones en Tamuda. Memoria resumen de las practicadas en 1942 presentada por Pelayo Quintero Atauri y Cecilio Giménez Bernal. MJSMHA 6. Instituto General Franco para la Investigación Hispano-Árabe. Larache.

QUINTERO ATAURI, Pelayo. 1944: Excavaciones en Tamuda. Memoria resumen de las practicadas en 1943 presentada por Pelayo Quintero Atauri y Cecilio Giménez Bernal. Memoria 7. Alta Comisaría de España en Marruecos. Delegación de Educación y Cultura. Imp. Martínez. Tetuán.

QUINTERO ATAURI, Pelayo. 1945: Excavaciones en Tamuda. Memoria resumen de las practicadas en 1944 presentada por Pelayo Quintero Atauri y Cecilio Giménez Bernal. Memoria 8. Alta Comisaría de España en Marruecos. Delegación de Educación y Cultura. Imprenta del Majzén. Tetuán.

QUINTERO ATAURI, Pelayo. 1946: Excavaciones en Tamuda. Memoria resumen de las practicadas en 1945 presentada por Pelayo Quintero Atauri y Cecilio Giménez Bernal. Memoria 9. Alta Comisaría de España en Marruecos. Delegación de Educación y Cultura. Imprenta del Majzén. Tetuán.

RAMOS, José; BERNAL, Darío; PARODI, Manuel J.; RAISSOUNI, Baraka; EL KHAYARI, Aziz; ZOUAK, Mehdi. 2015: "Valoración de yacimientos y de registros arqueológicos previos. De Montalbán a Meknassi". En B. RAISSOUNI, D. BERNAL, A. EL KHAYARI, J. RAMOS y M. ZOUAK (eds.): Carta Arqueológica del Norte de Marruecos (2008-2012). Prospección y yacimientos, un primer avance, pp. 29-64. Vol. I. Colección Villes et sites archéologiques du Maroc. Ministerio de Cultura del Reino de Marruecos-Universidad de Cádiz. Cádiz.
REMACHA TEJADA, José R. 2007: "El estatuto internacional del Protectorado español en Marruecos tras la Conferencia de Algeciras (1912-1956)". En J.A. DEL VALLE, J. VERDÚ y J.D. TORREJÓN (coords.): España y Marruecos en el centenario de la Conferencia de Algeciras, pp. 67-80. Dykinson. Madrid.

R'HONI, Alfaquih. 1953: Historia de Tetuán (traducida por Mohammad Ibn Azzuz Haquim). Tetuán.

RUIZ-BRAVO ZUBILLAGA, Estanislao. 1945: Índice legislativo de la Zona de Protectorado Español en Marruecos. Madrid.

SERRALLOLA URQUIDI, Joan. 1998: "La guerra de África (1859-1860). Una revisión". Ayer, 29, pp. $139-159$.

SUÁREZ FERNÁNDEZ, Luis. 1986: Franco. La historia y sus documentos. Urbión. Madrid.

TARRADELL MATEU, Miquel. 1960: Historia de Marruecos. Marruecos Púnico. Tetuán.

THOUVENOT, Raymond. 1938: "Une inscription latine du Maroc". Revue d'Etudes Latines, XVI, pp. 266-268. París.

TISSOT, Charles. 1877: "Recherches sur la géographie comparée de la Maurétanie Tingitane". Mémoires présentés par divers savants à l'Académie des Inscriptions et Belles-Lettres, 1è série, t. IX, pp. 139-322. París.

VERDUGO SANTOS, Javier; PARODI ÁLVAREZ, Manuel J. 2010: "La gestión del Patrimonio Arqueológico en el antiguo Protectorado español en el Norte de Marruecos. Gestión, administración, normativas". SPAL, 17, pp. 9-25.

ZOUAK, Mehdi; PARODI ÁLVAREZ, Manuel J. 2011: "Pelayo Quintero y el Arqueológico de Tetuán". En M.J. PARODI y E. GOZALBES (dirs. ed.): $P e-$ layo Quintero en el primer centenario de 1912, pp. 325-352. Diputación de Cádiz. Cádiz.

ZOUAK, Mehdi; PARODI ÁLVAREZ, Manuel J. 2012: "Apuntes históricos sobre el Museo Arqueológico de Tetuán". Actas de las III Jornadas de Arqueología y Prehistoria del Campo de Gibraltar. Almoraima. Revista de Estudios campogibraltareños, 42, pp. 47-72. 